WellBeing International

WBI Studies Repository

$12-1975$

\title{
Vocalizations of Isolated Piglets. II. Some Environmental Factors
}

D. Fraser

University of Edinburgh

Follow this and additional works at: https://www.wellbeingintlstudiesrepository.org/comski

Part of the Animal Studies Commons, Comparative Psychology Commons, and the Other Animal Sciences Commons

\section{Recommended Citation}

Fraser, D. (1975). Vocalizations of isolated piglets. II. Some environmental factors. Applied Animal Ethology, 2(1), 19-24.

This material is brought to you for free and open access by WellBeing International. It has been accepted for inclusion by an authorized administrator of the WBI Studies Repository. For more information, please contact wbisr-info@wellbeingintl.org.

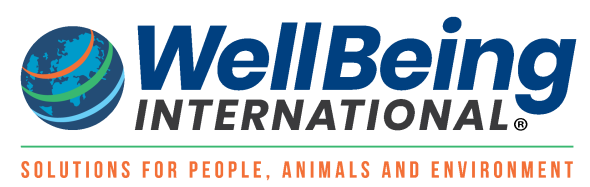




\title{
Vocalizations of Isolated Piglets. II. Some Environmental Factors
}

\author{
D. Fraser \\ University of Edinburgh
}

\begin{abstract}
The vocalizations of suckling piglets were studied during brief tests which involved social isolation, restriction of movement, and exposure to unfamiliar surroundings. Similar trends were shown in most cases by the three classes of call studied - closed mouth grunts, open mouth grunts, and squeals. The rate of calling was much lower when a piglet was in the home pen than when alone in an unfamiliar pen, and more calls were given in both situations when the animal's movement was restricted by caging. The presence of the dam and four littermates in unfamiliar surroundings caused a large reduction in calling, part of which was seen with only the dam present, and part with only the littermates. Provision of familiar bedding in the unfamiliar situation had no effect. Aspects of piglets' adaptation to environmental and social change are discussed.
\end{abstract}

\section{INTRODUCTION}

Early-weaned piglets show a number of behavioural changes which may reflect difficulty in adapting to their new situation (Fraser, 1974). However, early weaning generally involves a number of environmental and social changes, including the initial unfamiliarity of the new surroundings, separation from the sow and in special cases from other littermates, and often some restriction of movement. There is little to indicate which of these and other factors have the greatest effect on the animals.

When piglets are first placed in early-weaning cages they often vocalize repeatedly. This reaction may last for several hours, or even for a number of days if social isolation is involved (unpublished observations). These vocalizations are of interest because they may reflect something of the difficulty with which the animals adapt to the new environment.

Similar sustained vocalizing is heard when suckling piglets are removed briefly from their home pens to unfamiliar surroundings away from other pigs. Relationships among the types of call given in this situation, and sources of variation in the response between and within litters, have been reported previously (Fraser, 1975). The following experiments explored some environmental factors which might affect this reaction, by exposing piglets to a variety of circumstances involving restriction of movement, unfamiliar physical surroundings, and separation from the dam and from littermates.

\section{METHOD}

A total of 96 piglets from 24 litters, aged 7 to 19 days and drawn from a Large White and Landrace herd, were studied in three experiments. The litters were housed in farrowing pens measuring approximately 
$2 \times 3 \mathrm{~m}$, each equipped with a farrowing crate and with about $1 \mathrm{~kg}$ of straw bedding which was replaced daily at about $10.00 \mathrm{~h}$. There were two main rooms containing eight and ten such pens, and two additional rooms containing two pens each. Litters were not used if any of the piglets had facial lacerations as caused by fighting during suckling.

The three experiments each involved a comparison of four treatments with 32 piglets from eight litters assigned to the treatments on a split litter basis. The order in which the treatments were used for the different litters was varied by two $4 \times 4$ Latin squares. The following combinations of treatments were used.

(1) In Experiment 1 the treatments involved restraint of movement, social isolation, and exposure to unfamiliar surroundings. For treatment $\mathrm{CH}$ (cage - home pen) a piglet was caught by hand and was placed in a metal and wire mesh cage, $805 \times 285 \times 450 \mathrm{~mm}$ high, in the corner of its own home pen. The caged piglet could see and hear its dam and its littermates which often crowded around the cage, but could not approach or touch them. In treatment CU (cage - unfamiliar pen) the cage was situated in the corner of an unoccupied pen of the same size and in the same room. Animals so tested could hear but not see other pigs. In treatments NH (no cage - home pen) and NU (no cage - unfamiliar pen) the piglet was caught and then released in its home pen or the unfamiliar pen respectively. Each test lasted 5 min.

(2) The treatments in Experiment 2 involved exposure to unfamiliar surroundings and separation from the dam and littermates, without any additional restriction of movement. Piglets were moved for testing to an unoccupied farrowing pen in a room which did not contain other animals. Just before a test the pen was equipped with the straw bedding from the test litter's home pen (treatment B - bedding), with the test piglet's dam and four of its littermates (treatment $\mathrm{DL}$ - dam and littermates), with the bedding plus the dam and litter-mates (treatment BDL), or with nothing (treatment $\mathrm{N}$ ). Each test lasted 5 min.

(3) In Experiment 3 the effects of isolation from the dam and from the littermates were studied separately. Piglets were tested for $3 \mathrm{~min}$ in the unoccupied farrowing pen used in Experiment 2. Just before a test the pen was equipped with the test animal's dam (treatment $D$ ), four of its littermates (treatment $L$ ), with both the dam and the littermates (treatment $\mathrm{DL}$ ) or with nothing (treatment $\mathrm{N}$ ).

Testing was usually done between 16.00 and $18.00 \mathrm{~h}$. Throughout each test the vocalizations of the experimental animal were recorded on a portable tape recorder. The microphone was attached to the end of a pole $1.2 \mathrm{~m}$ long which was moved so as to keep the microphone within $0.3 \mathrm{~m}$ from the test piglet. In Experiments 1 and 2 the recordings were analysed by counting the number of closed mouth grunts, open mouth grunts and squeals (as described by Fraser, 1975) given by the experimental animal. In Experiment 3 the four littermates often vocalized, making it difficult to count the calls of the test animal. It was generally possible, however, to distinguish whether the test animal had given a particular type of call in a certain interval of time. Accordingly the recordings were analysed by counting the number of 5-see intervals from the beginning in which the test animal gave each of the three types of call.

\section{RESULTS}

In Experiment 1 both the restriction of movement by caging and the social isolation in unfamiliar surroundings appeared to influence the animals' behaviour. Fig. 1 shows the mean ( \pm S.E.) number of calls of the three types given by the piglets in the four treatments. Latin square analysis of variance indicated a significant difference among treatments for closed mouth grunts $(P<0.01)$, open mouth grunts $(P<0.05)$, and squeals $(P<0.001)$, while litter of origin and the order in which the treatments were used had no substantial effects. Since few pigs gave open mouth grunts or squeals in treatments $\mathrm{NH}$, the results for these measures were also analysed by the non-parametric Wilcoxon matched-pairs signed- 
ranks test which showed that there were fewer calls of both types in treatments $\mathrm{NH}$ and $\mathrm{CH}$ than in treatments $\mathrm{NU}$ and $\mathrm{CU}$ respectively, fewer calls of both types in treatment $\mathrm{NU}$ than in $\mathrm{CU}$, and fewer squeals in treatment $\mathrm{NH}$ than in $\mathrm{CH}(P<0.05$ or 0.01 , two-tailed, in all cases).

In the second experiment, all three classes of vocalization were much less common when the dam and littermates were present in the pen, but the provision of familiar bedding had no substantial effect. The mean ( \pm SE.) number of calls of the three types given in each treatment is shown in Fig. 2. Latin square analysis of variance showed that the scores differed according to treatment $(P<0.001$ for closed mouth grunts, 0.05 for open mouth grunts, and 0.01 for squeals) but not according to litter or the order in which the treatments were used. Comparison of the treatments in pairs by the Wilcoxon matched-pairs signedranks test showed no significant difference between treatments $N$ and $B$, nor between $D L$ and $B D L$, but the former two and the latter two treatments differed in all three classes of call $(P<0.05$ or 0.01 , twotailed, in all cases).

Fig. 1. The mean ( \pm S.E.) number of closed mouth grunts, open mouth grunts and squeals given by the piglets of Experiment 1 when tested uncaged in the home pen $(\mathrm{NH})$, caged in the home pen $(\mathrm{CH})$, uncaged in an unfamiliar pen (NU), or caged in an unfamiliar pen (CU).

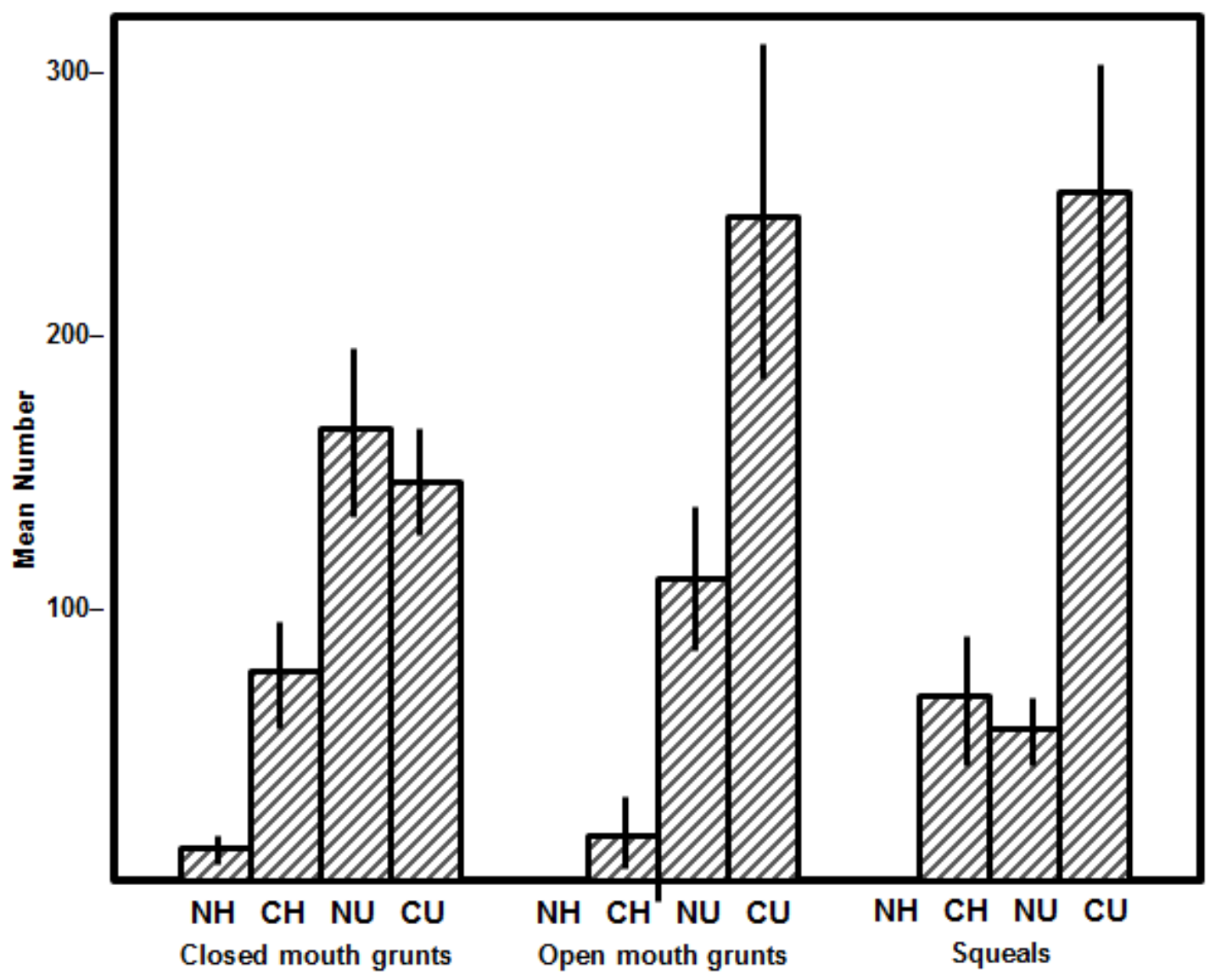

In the second experiment, all three classes of vocalization were much less common when the dam and littermates were present in the pen, but the provision of familiar bedding had no substantial effect. The mean ( \pm S.E.) number of calls of the three types given in each treatment is shown in Fig. 2. Latin square analysis of variance showed that the scores differed according to treatment $(P<0.001$ for closed mouth 
grunts, 0.05 for open mouth grunts, and 0.01 for squeals) but not according to litter or the order in which the treatments were used. Comparison of the treatments in pairs by the Wilcoxon matched-pairs signedranks test showed no significant difference between treatments $N$ and $B$, nor between $D L$ and $B D L$, but the former two and the latter two treatments differed in all three classes of call $(P<0.05$ or 0.01 , twotailed, in all cases).

Experiment 3 indicated that the presence of the dam and the presence of the littermates both contributed to a reduction in the amount of calling by the test piglet. Fig. 3 gives the mean $( \pm$ S.E.) percentage of 5 set intervals in which piglets gave the three types of call in the four treatments. Non-parametric Friedman two-way analysis of variance showed a significant difference among treatments in the case of closed mouth grunts and squeals $(P<0.001$ in both cases). The Wilcoxon matched-pairs signed-ranks test showed a significant difference between all treatments in the scores for closed mouth grunts except between treatments $\mathrm{N}$ and $\mathrm{L}$, and in scores for squeals except between treatments $\mathrm{L}$ and $\mathrm{D}(P<0.05$ or 0.01 , two-tailed, in all cases).

Fig. 2. The mean ( \pm S.E.) number of closed mouth grunts, open mouth grunts and squeals given by the piglets of Experiment 2 when tested in an unfamiliar pen with no additions $(\mathrm{N})$, in the presence of bedding from the home pen (B), in the presence of the dam and four littermates (DL) or in the presence of the bedding, the dam, and four littermates (BDL).

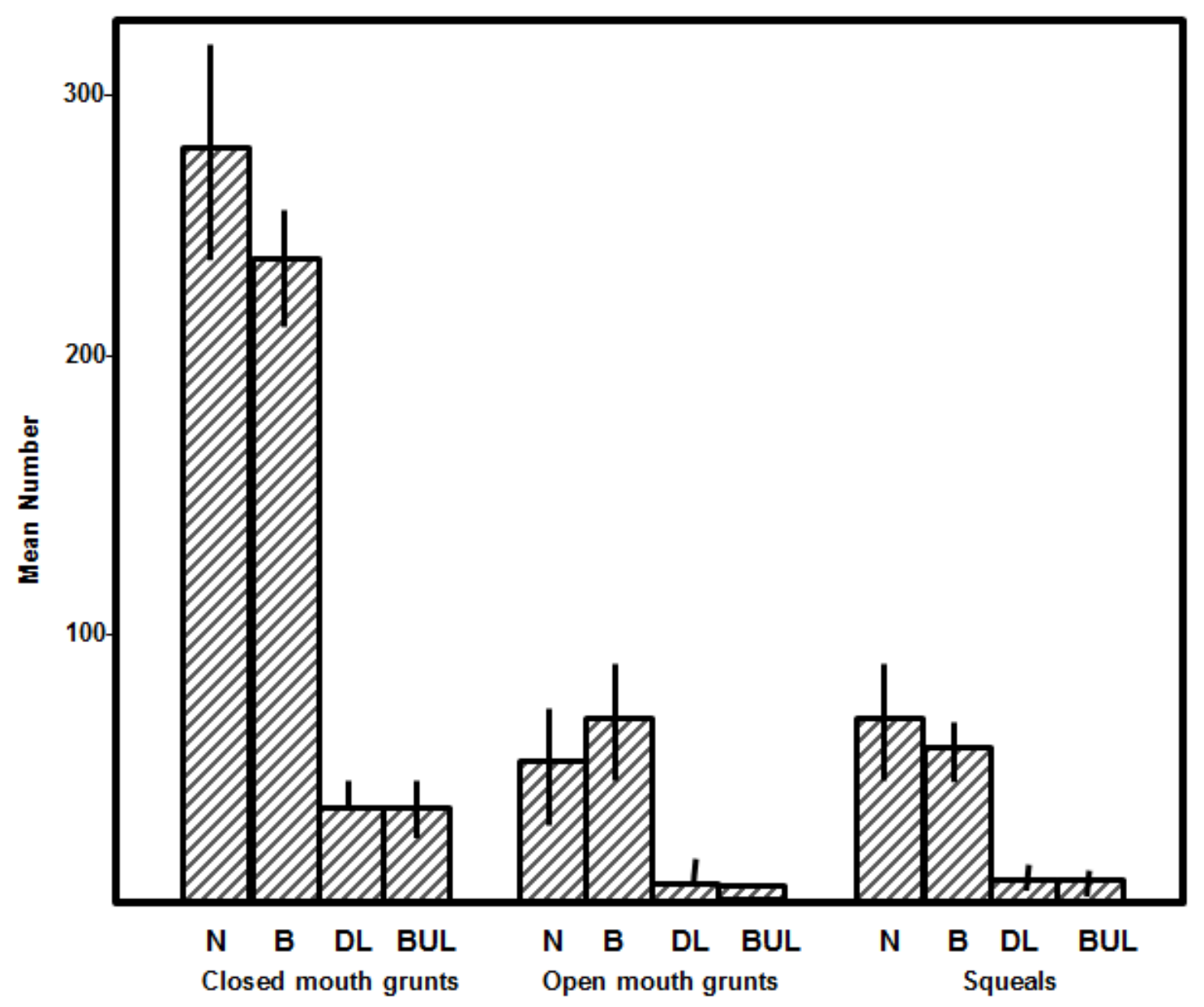


Fig. 3. The mean ( \pm S.E.) percentage of 5-sec intervals in which closed mouth grunts, open mouth grunts, and squeals were given by the piglets of Experiment 3 when tested in an unfamiliar pen with no additions (N), in the presence of four littermates (L), in the presence of the dam (D), or in the presence of both the dam and four littermates (DL).

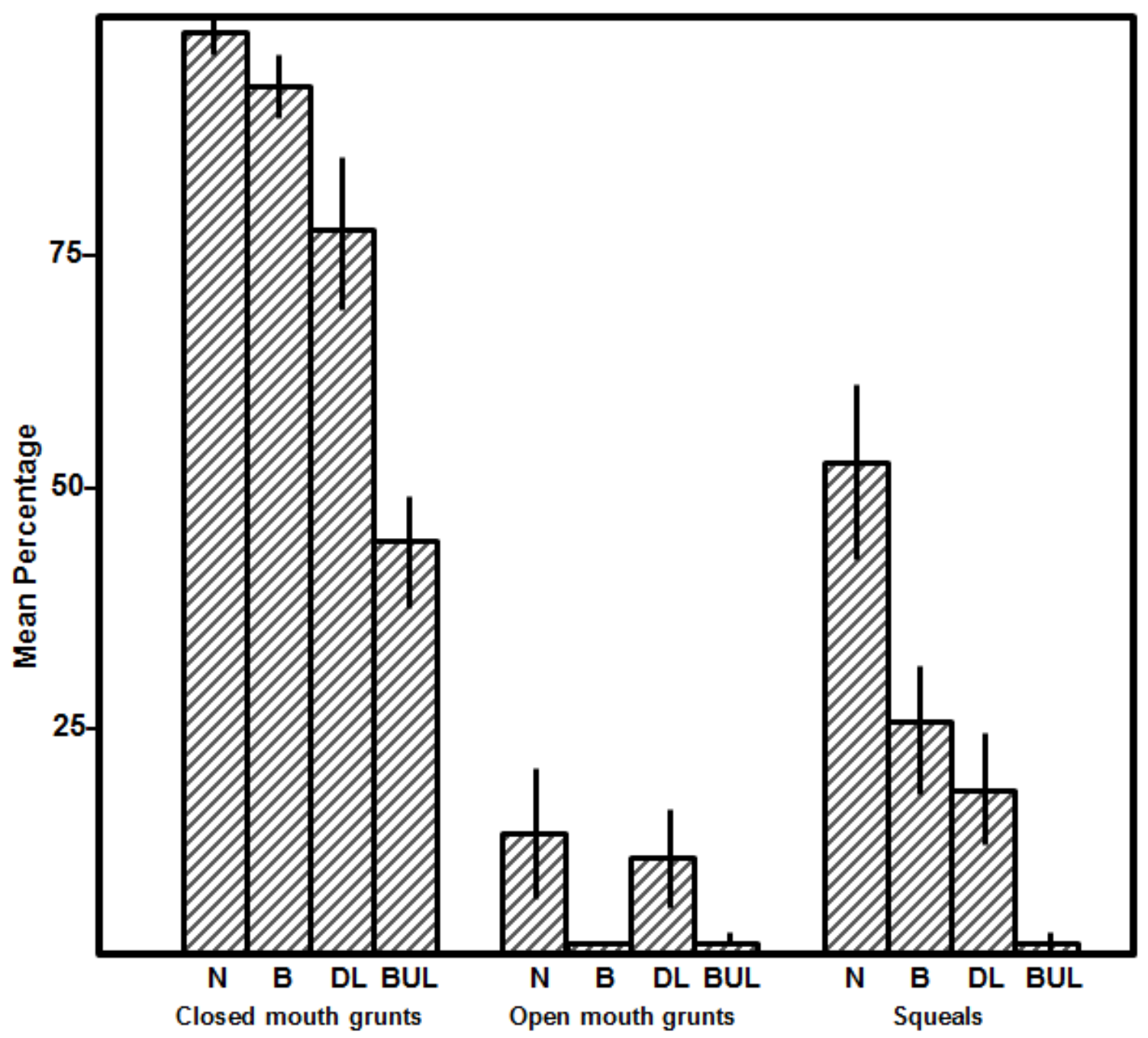

\section{DISCUSSION}

Relationships among the three types of call have been studied previously (Fraser, 1975). In the present study the three measures usually followed similar trends under the different experimental conditions. There is one exception in Experiment 1: open mouth grunts and squeals were much more common in treatment $\mathrm{CU}$ than in treatment $\mathrm{NU}$, while closed mouth grunts showed a slight trend in the opposite direction. However, the piglets in treatment CU were giving, on average, more than 600 calls in the 5-min test. In the previous study, open mouth grunts and squeals apparently began to replace closed mouth grunts at such high rates of calling. A second exception to the overall association between the calls is the different trends shown by open mouth grunting and squealing in Experiment 3 , as discussed below.

The results indicate that both restriction of movement and separation from social companions influenced the piglets' behaviour, while the limited attempt to make the surroundings more familiar by providing bedding from the home pen had no tangible effect. 
The importance of restriction of movement among battery-reared piglets has been emphasized by Marx (1973) who noted several behavioural changes including a reduction in sleeping among piglets in cages after the fifth week of life. Marx attributes such changes to the increasing spatial restriction caused by the rapid growth of the animals in an area of limited size.

Experiment 2 showed a large reduction in calling when the dam and littermates were present in the test pen. In Experiment 3 the effects of the dam and the littermates were studied separately. Both apparently contributed to the reduction in calling. There was more closed mouth grunting in the presence of the littermates alone, while open mouth grunts were given by several piglets in the presence of the dam alone, but not in the presence of the litter-mates. This reinforces the author's impression that open mouth grunting - particularly a series of such calls in rapid succession sounding like a hoarse laugh - is especially common when a piglet is reunited with its dam after a brief separation. Despite these anomalous details, the results suggest that the strong reaction of a piglet to separation from the dam can be attenuated by the presence of familiar litter-mates.

\section{ACKNOWLEDGEMENTS}

This work was supported by the Agricultural Research Council with the co-operation of Professor F.W.H. Elsley and Dr D.G.M. Wood-Gush, and of the pig unit staff.

\section{REFERENCES}

Fraser, D., 1974. Behaviour at three weeks. Pig Farming, 22 (10): 61-71.

Fraser, D., 1975. Vocalizations of isolated piglets. I. Sources of variation and relationships among measures. Appl. Anim. Ethol., 1: 387-394.

Marx, D., 1973. Vergleichende Untersuchungen uber das Verhalten von Saugferkeln und fruhabgesetzten Ferkeln in Kafiggruppenhaltung (Batteriehaltung). Berl. Munch. Tierarztl. Wochenschr., 86: 289-295. 